\title{
Qualidade da água na Bacia Hidrográfica do Açude Santa Cruz do Apodi, Rio Grande do Norte
}

\section{Water quality in the Santa Cruz of the Apodi watershed, Rio Grande do Norte, Brazil}

\author{
Wagner Bandeira da Silva ${ }^{\left({ }^{D} 1\right.}$; Joel Medeiros Bezerra ${ }^{(D)}{ }^{2}$; Alana Ticiane Alves do Rêgo ${ }^{(D)}$ \\ ${ }^{1}$ Graduado em Engenharia Ambiental e Sanitária, Universidade Federal Rural do Semi-Árido, Pau dos Ferros, Rio Grande do Norte, +5588996663988, \\ wagnerbandeira2010@ hotmail.com; ${ }^{2}$ Doutor em Engenharia Agrícola, Professor da Universidade Federal Rural do Semi-Árido, Pau dos Ferros, Rio Grande do Norte, \\ joel.medeiros@ufersa.edu.br; ${ }^{3}$ Mestranda em Ciências Naturais, Universidade do Estado do Rio Grande do Norte, Mossoró, Rio Grande do Norte, \\ alana ticiane10@hotmail.com
}

\section{A R T I G O}

Recebido: $13 / 04 / 2020$

Aprovado: 25/02/2021

Palavras-chave:

Semiárido

Análise de componentes

principais

Conservação de recursos hídricos

\begin{abstract}
R E S U M O
Os impactos adversos na Bacia Hidrográfica do Açude Santa Cruz do Apodi (BHASCA) inviabilizam os usos múltiplos das águas em determinadas áreas, fazendo-se necessário compreender a qualidade desse recurso por meio de uma avaliação pontual de suas características físicas, químicas e biológicas. Nesse contexto, o presente trabalho teve como objetivo caracterizar os principais componentes que influenciam na qualidade das águas da bacia hidrográfica do açude Santa Cruz do Apodi-RN, no período de 2008 a 2016, considerando a variabilidade sazonal. A metodologia consistiu em realizar mediante levantamento de dados secundários, oriundos dos relatórios do Programa Água Azul, uma análise dos parâmetros da qualidade da água na BHASCA, por meio da aplicação de técnicas estatísticas de matriz de correlação linear de Pearson e Análise de Componentes Principais (ACP). A correlação linear possibilitou identificar a dependência entre parâmetros físico-químicos e biológicos. A ACP sintetizou a informação contida no conjunto das variáveis. Nessa perspectiva, observou-se uma susceptibilidade da BHASCA a processos de eutrofização, os quais podem estar comprometendo e/ou limitando os usos múltiplos das águas na referida bacia, afetando a manutenção da biodiversidade.
\end{abstract}

\section{A B S T R A C T}

Key words:

Semi-arid

Principal component analysis

Conservation of water resources

\begin{abstract}
The adverse impacts in the Santa Cruz do Apodi Watershed Basin (BHASCA) prevent multiple uses of water in certain areas, making it necessary to understand the quality of this resource through a specific assessment of its physical, chemical and biological characteristics. In this context, the present study aimed to characterize the main components that influence the water quality of the watershed of the Santa Cruz do Apodi-RN reservoir, from 2008 to 2016, considering the seasonal variability. The methodology consisted of conducting, by means of a survey of secondary data, derived from the reports of the Água Azul Program, an analysis of the water quality parameters at BHASCA, through the application of statistical techniques of Pearson's linear correlation matrix and Principal Components Analysis (ACP). The linear correlation made it possible to identify the dependence between physical-chemical and biological parameters. ACP synthesized the information contained in the set of variables. In this perspective, BHASCA's susceptibility to eutrophication processes was observed, which may be compromising and/or limiting the multiple uses of water in the referred basin, affecting the maintenance of biodiversity.
\end{abstract}

\section{INTRODUÇÃO}

A água possui importância primordial para a manutenção da vida no planeta. Logo, falar da relevância dos conhecimentos sobre a água em suas diversas dimensões é falar da conservação e do equilíbrio da biodiversidade e das relações de dependência entre seres vivos e ambientes naturais (BACCI; PATACA, 2008, p. 211), pois a qualidade da água tem grande impacto na saúde humana, sendo essencial para o funcionamento dos ecossistemas (MORAES et al., 2018).

Entretanto, mesmo sendo um recurso renovável e limitado, na medida em que há um maior crescimento econômico e populacional, menos se respeita o ciclo natural da água e consequentemente aumenta-se a degradação, tornando-a imprópria para consumo. A qualidade da saúde pública e o
Revista Verde

ISSN 1981-8203

Pombal, Paraíba, Brasil v. 16, n.2, abr.-jun, p. 164-173, 2021 doi: $10.18378 /$ rvads.v16i2.7837

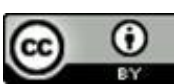


comprometimento dos recursos hídricos podem estar relacionados a diversos fatores como a sazonalidade decorrente das condições climáticas (GUEDES et al., 2017), poluição por efluentes domésticos, industriais e deflúvio superficial urbano e agrícola (STOLF; MOLZ, 2017) e até mesmo questões mais específicas como a geologia, solo, temperatura e outros elementos naturais (BRAGA et al., 2017).

Dessa forma, em decorrência do apresentado e da dificuldade de compreensão e harmonização de informações referentes à condição da água, a caracterização de sua qualidade se torna imprescindível, principalmente com o auxílio da estatística (GARDIMAN JUNIOR, 2015, p. 236). Sendo assim, recentemente alguns autores como Palácio et al. (2011), Bertossi et al. (2013) e Barcelos et al. (2017) têm utilizado de recursos estatísticos multivariados ou não-paramétricos, voltados a otimizar algumas análises para redução da dimensionalidade do conjunto de dados, assim como formação de componentes com emprego de variáveis mais expressivas para o monitoramento da qualidade de água. Para Varela et al. (2017, p. 2):

O monitoramento da qualidade da água é um dos principais instrumentos de sustentação de uma política de planejamento e gestão de recursos hídricos, visto que funciona como um sensor que possibilita o acompanhamento do processo de uso dos corpos hídricos, apresentando seus efeitos sobre as características qualitativas das águas, visando subsidiar as ações de controle ambiental.

Sendo assim, para um melhor conhecimento sobre a qualidade real da água de um corpo hídrico é imprescindível à avaliação pontual de suas características físicas, químicas e biológicas. Com a utilização de parâmetros físico-químicos e microbiológicos é possível avaliar a qualidade das águas por meio do suporte de técnicas estatísticas, principalmente em regiões semiáridas, que são de elevada vulnerabilidade socioambiental.

$\mathrm{Na}$ região Oeste do Estado do Rio Grande do Norte, localiza-se a Bacia Hidrográfica do Rio Apodi-Mossoró/RN BHRAM/RN. Seu afluente a montante da Barragem de Santa Cruz do Apodi-RN, contempla o alto e médio superior curso da BHRAM/RN, a qual vem sofrendo com alterações antrópicas relacionadas com atividades econômicas. Em praticamente toda a extensão da bacia ocorrem fatores identificados como conflitos em relação ao uso da água relacionados com a sociedade (SILVA et al, 2020), inviabilizando, em determinadas áreas os usos múltiplos de suas águas, decorrente da presença das atividades de captação para abastecimento humano, dessedentação animal, agricultura irrigada, além de ser corpo hídrico receptor de efluentes domésticos.

Apesar dessa bacia está inserida em um recorte territorial de transição do meio rural, com a ocorrência de pequenos aglomerados urbanos e cidades em desenvolvimento, ressalta-se a existência de conflitos que recaem na exigência de melhores padrões de qualidade da água para usos mais restritivos como abastecimento humano, os quais são comprometidos tanto pela limitação quantitativa, como qualitativa, decorrente da ocorrência da presença de barramentos hidráulicos, em propriedades privadas, a montante, os quais habitualmente são empregados para práticas de agricultura e pecuária, as margens do rio e dos barramentos, propiciando a lixiviação de fertilizantes e defensivos agrícolas. Combinando a ocorrência das descargas de efluentes e esgoto em toda extensão da bacia vertente (OLIVEIRA et al, 2009), decorrente das áreas urbanizadas. Além da devastação da mata ciliar, causando o assoreamento das margens do rio, e a contaminação das águas pelo incorreto descarte de resíduos domésticos (OLIVEIRA; QUEIROZ, 2008).

Nesse contexto, esse trabalho teve como objetivo caracterizar os principais componentes que influenciam na qualidade das águas da bacia hidrográfica do açude Santa Cruz do Apodi-RN, no período de 2008 a 2016, considerando a variabilidade sazonal, por meio da análise multivariada.

\section{MATERIAL E MÉTODOS}

\section{Área de estudo}

A Bacia Hidrográfica do Açude Santa Cruz do Apodi BHASCA, localiza-se na região Oeste Potiguar, no estado do Rio Grande do Norte, entre as coordenadas UTM 533816 - 660566 m E: 9272883 - 9384694 m N (Figura 01), apresenta área de $4.439 \mathrm{~km}^{2}$.

No geral, os afluentes e rios desta região apresentam um regime hidrológico "intermitente e sazonal, reflexo direto das precipitações escassas e irregulares, associadas à alta taxa de evaporação hídrica" (SOUZA et al., 2012, p. 288). No entanto, alguns canais são perenizados pela presença de barramentos artificiais, como é o caso do canal principal do rio Apodi Mossoró, localizado a jusante do barramento hidráulico da barragem de Santa Cruz em Apodi, é considerado um rio perene, devido a sua regularização de vazão ocasionada pelo barramento artificial.

O clima predominante é do tipo BSwh, da classificação climática de Köppen, caracterizado por um clima muito quente e semiárido, com a estação chuvosa se atrasando para o outono. No extremo sudoeste da bacia, correspondendo às suas nascentes, ocorre o tipo Aw', caracterizado por um clima tropical chuvoso com verão seco e estação chuvosa se adiantando para o outono (ALVARES, 2013). Silva et al. (2012) realizaram estudos sobre a distribuição espacial da precipitação na região Oeste do estado do Rio Grande do Norte, onde os maiores acumulados foram registrados nos meses de março.

Cabe ressaltar, ainda, que entre os anos de 2012 e 2017, o estado do Rio Grande do Norte passou por 05 (cinco) anos de estiagem, nesse período observou-se uma sequência de cinco anos de precipitações abaixo da média para o período chuvoso, consequentemente, muitos reservatórios da região não receberam aporte hídrico suficiente (MACHADO et al., 2017).

A geologia da região pertence, em parte, ao Escudo Cristalino Brasileiro, representado por rochas do Pré-cambriano, Complexo Presidente Juscelino, Complexo Caicó, Jucurutu e Ceará. As litologias predominantes são os gnaisses, quartzolitos, xistos, calcários cristalinos metamórficos e graníticos (CPRM, 2016). Quanto às classes de solos mais comuns encontrados na bacia destacam-se os Luvissolos, Neossolos e Latossolos (IBGE, 2018).

A vegetação predominante nessa região é a do tipo Caatinga, que serve de base para exploração econômica e industrial de diversas cadeias econômicas, desde agricultura, pecuária e turismo (SPINELLI, 2014). 
Figura 01. Localização da Bacia Hidrográfica do Açude Santa Cruz do Apodi, Rio Grande do Norte, Brasil

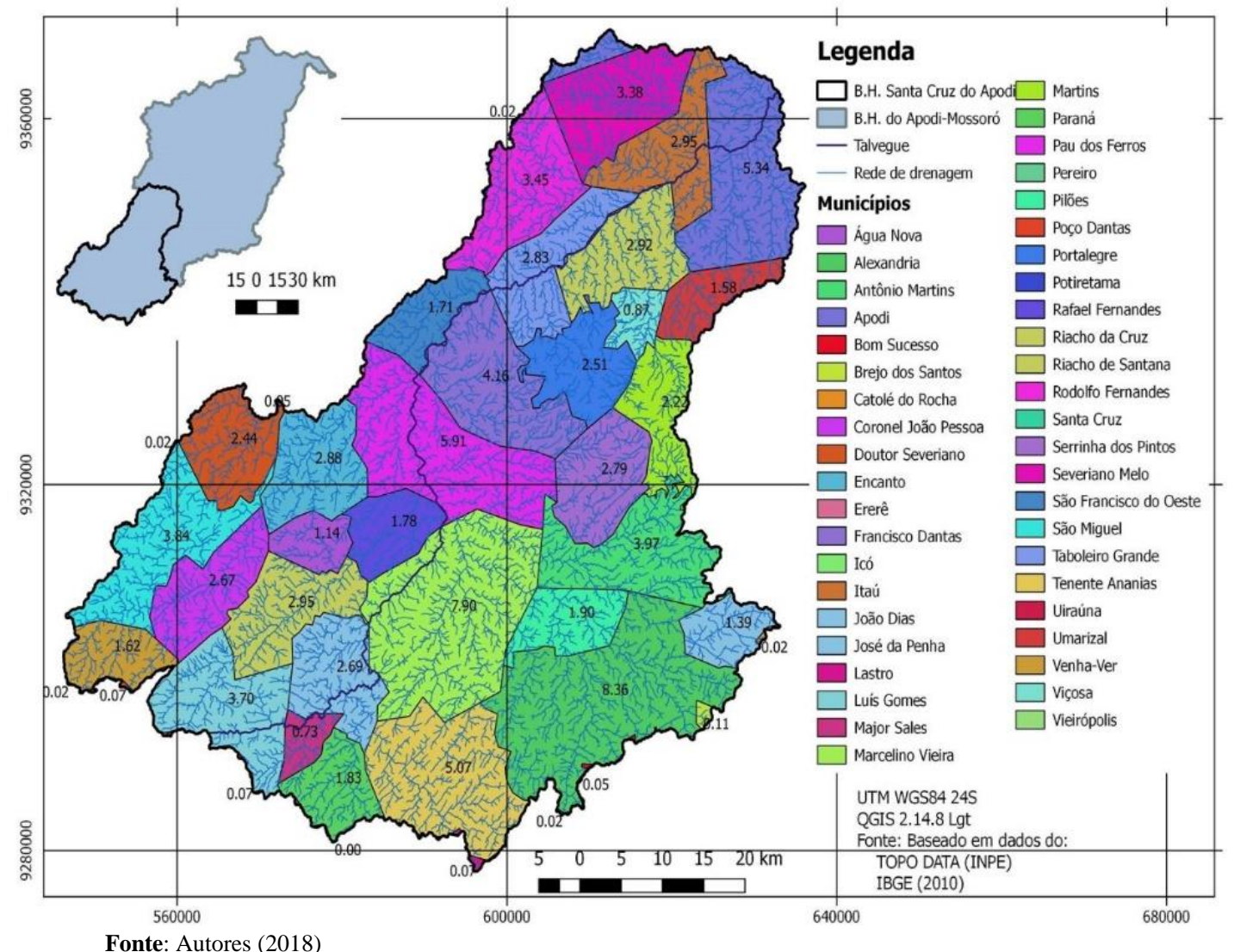

\section{Procedimentos metodológicos}

A pesquisa classifica-se como exploratória, uma vez que, de acordo com Prodanov e Freitas (2013, p. 52), "busca-se proporcionar informações relevantes ao assunto investigado visando maior familiaridade com o problema". Esse trabalho resultou de um levantamento bibliográfico de dados secundários oriundos dos relatórios do Programa Água Azul, com a finalidade de adquirir informações relacionadas à qualidade das águas superficiais da Bacia Hidrográfica do Açude Santa Cruz do Apodi -BHASCA.

Com o objetivo de obter maiores informações sobre o monitoramento dos parâmetros físico-químicos e biológicos da qualidade da água dos reservatórios superficiais da BHASCA, foram realizadas consultas aos relatórios anuais do Programa Água Azul correspondendo aos anos de 2008 a 2016 (Tabela 1). Esse Programa consiste na medição e verificação periódica de parâmetros de qualidade de água, usada para o acompanhamento da condição atual, sua evolução e controle da qualidade do corpo de água, além de possibilitar a projeção de situações futuras. $\mathrm{O}$ Programa tem por objetivo realizar o monitoramento sistemático da qualidade dos principais corpos d'água interiores Norteriograndenses, verificando os trechos que estão com parâmetros em desacordo com as condições e padrões estabelecidos pela Resolução CONAMA N. ${ }^{\circ}$ 357/2005.

Os relatórios apresentam dados sobre parâmetros de qualidade da água: Sólidos Totais Dissolvidos (STD), Nitrogênio Total (NT), Demanda Bioquímica de Oxigênio (DBO), Fósforo
Total (FT), Carbono Orgânico Total (COT) Oxigênio Dissolvido (OD), Turbidez (TUB), potencial Hidrogeniônico (pH), Temperatura da Água (TA), Coliformes Termotolerantes (CT), Índice de Qualidade da Água (IQA), Clorofila "a" (CRF), Teor de óleos e graxas (TOG) e Salinidade (SAL).Nos anos 2011, 2012 e 2015 obteve-se 02 (dois) relatórios semestrais, enquanto para os demais anos em estudo foram adquiridos relatórios anuais. No ano de 2013 não houve disponibilização dos dados por parte do Programa Água Azul. Dessa forma, para esse estudo foram amostrados 13 (treze) pontos ao longo da BHASCA, dos quais apresentam-se espacializados na Figura 2.

Tabela 1. Relatórios do programa Água Azul avaliados no estudo.

\begin{tabular}{cc}
\hline Ano & Período da campanha \\
\hline 2008 & Agosto a novembro \\
2009 & Abril a julho \\
2010 & Junho a setembro \\
& Fevereiro a julho \\
2011 & Setembro a dezembro \\
& Setembro a dezembro \\
& Março a maio \\
2012 & Agosto a outubro \\
2014 & Julho a agosto \\
2015 & Janeiro a março \\
2016 & Julho a agosto \\
& Março a maio \\
\hline
\end{tabular}


Figura 2. Localização dos Pontos de amostragem distribuídos na Bacia Hidrográfica do Açude Santa Cruz do Apodi, Rio Grande do Norte, Brasil.

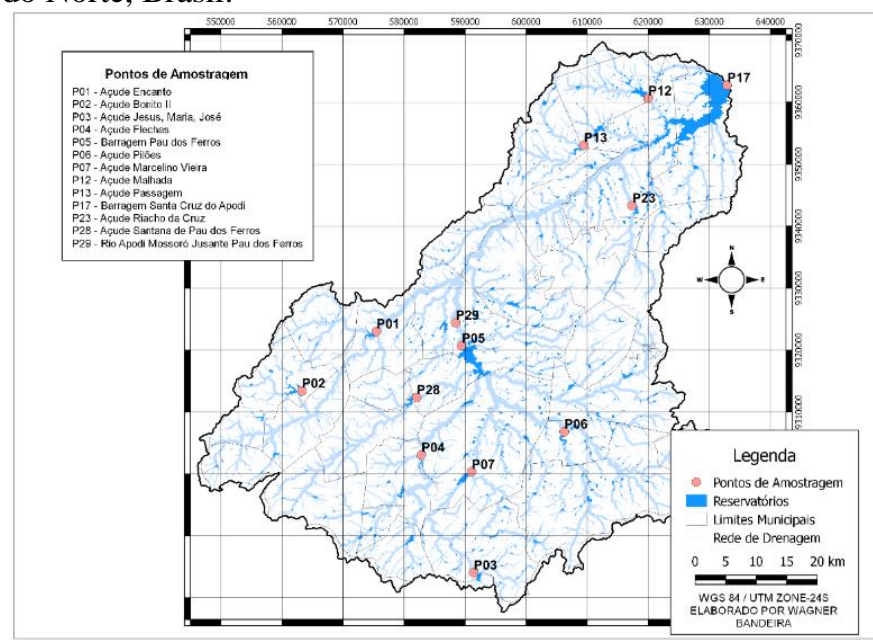

Fonte: Autores (2018)

\section{Análise de Componentes Principais}

A primeira etapa consistiu em transformar a matriz de dados originais em uma matriz de correlação para os 14 (quatorze) parâmetros de qualidade de água analisados neste estudo, com o objetivo de eliminar o problema de escalas e unidades diferenciadas em que as variáveis são medidas (ROCHA; PEREIRA, 2016, p. 179).

Dessa forma, calculou-se os coeficientes de correlação de Pearson. A importância linear das variáveis na correlação é determinada pelos intervalos dos coeficientes que variam de -1 a 1, sendo que o sinal, negativo ou positivo, indica a direção, enquanto que o valor indica a magnitude da correlação. Para a sua classificação quanto a sua magnitude consideram-se valores superiores a 0,50como uma forte correlação (OLIVEIRA et al., 2018).

Tabela 2. Correlação entre parâmetros de qualidade de água na Bacia Hidrográfica do Açude Santa Cruz do Apodi com ênfase nos coeficientes que mais se repetem nas matrizes de correlação de Pearson superior a 50\%, por período sazonal.

\begin{tabular}{ccc}
\hline Período de Monitoramento & Variável & Parâmetro correlacionado \\
\hline Agosto a novembro de 2008 & Teor de Óleos e Graxas & TA; pH; OD; COT \\
Abril a julho de 2009 & Teor de Óleos e Graxas & FT; TUB; SAL; \\
Junho a setembro de 2010 & Demanda Bioquímica de Oxigênio & NT; STD; CRF \\
Fevereiro a julho de 2011 & Demanda Bioquímica de Oxigênio & FT; TUB; CRF \\
Setembro a dezembro de 2011 & Clorofila "a” & TUB; NT; TOG \\
Março a maio de 2012 & Nitrogênio Total & CRF; FT; TOG; STD \\
Agosto a outubro de 2012 & Clorofila "a” & STD; TUB; DBO \\
Julho a agosto de 2014 & Fósforo Total & OD; DBO \\
Janeiro a março de 2015 & Clorofila "a” & TUB; STD; CT; DBO \\
Julho a agosto de 2015 & Temperatura da Amostra & OD; STD; SAL \\
Março a maio de 2016 & Demanda Bioquímica de Oxigênio & NT; STD \\
\hline
\end{tabular}

STD: Sólidos Totais Dissolvidos; NT: Nitrogênio Total; DBO: Demanda Bioquímica de Oxigênio; FT: Fósforo Total; COT: Carbono Orgânico Total; OD: Oxigênio Dissolvido (OD); TUB: Turbidez; pH: potencial Hidrogeniônico; TA: Temperatura da Água; CT: Coliformes Termotolerantes; CRF: Clorofila "a"; TOG: Teor de óleos e graxas, e; SAL: Salinidade.
Em seguida fez-se emprego da técnica de Análise de Componentes Principais (ACP), a qual tem finalidade de condensar a informação contida em várias variáveis originais em um conjunto menor com uma perda mínima de informação (HONGYU et al., 2016, p.83). Nesse sentido, sintetizou-se a maior quantidade da informação original em duas variáveis latentes ortogonais denominadas componentes principais, que são combinações lineares das variáveis originais, criadas com os dois maiores autovalores da matriz de covariância dos dados, desta maneira, diminuindo a dimensionalidade do conjunto de variáveis e facilitando a interpretação da independência entre ela. Posteriormente, construiu-se os gráficos Biplot para permitir a avaliação visual das distâncias entre unidades, indicar agrupamento de unidades, bem como exibir variações e correlações das variáveis avaliadas.

O critério adotado para a escolha do número de componentes foi selecionar aquelas que apresentaram autovalores (desvio padrão) acima de um, pois são aquelas que geram componentes com quantidade relevante de informação das variáveis originais e conseguiram sintetizar uma variância acumulada acima de 70\% (HONGYU et al., 2016). Como forma de simplificar ainda mais, optou-se por escolher as duas componentes com maiores variâncias explicadas (CP1 e CP2). Esse método é coerente, uma vez que o primeiro e o segundo componente principal explicam a maior parte da variância total (JOSÉ et al., 2013). Para as análises dos dados fez-se uso da técnica de ACP, no qual, empregou-se as funções princomp e prcomp por meio do software R versão 3.2.3.

\section{RESULTADOS E DISCUSSÃO}

A partir da análise sazonal da matriz de correlação de Pearson por período de monitoramento identificou-se as variáveis que se destacaram ao apresentarem resultados de correlação superior a 0,5 com pelo menos duas outras, tais dados podem ser constatados na Tabela 2 . 
Percebe-se uma forte correlação entre sólidos totais dissolvidos (STD) e os parâmetros teor de óleos e graxas, clorofila "a", coliformes termotolerantes, demanda bioquímica de oxigênio (DBO), turbidez, $\mathrm{pH}$, temperatura da amostra, nitrogênio total e salinidade. Palácio et al. (2011) afirmam que os STD são um dos principais constituintes presentes nas águas superficiais e sua origem pode ocorrer de forma natural (processos erosivos, organismos e detritos orgânicos) ou antropogênica (lançamento de resíduos sólidos e efluentes líquidos). Diante disso, devido a área de estudo apresentar atividades antropogênicas em suas adjacências, os níveis de sólidos em suas diversas frações fornecem indicações preliminares para a caracterização química da água, conforme foi indicado também pela presença de outros parâmetros.

A turbidez apresentou correlação significativa com os sólidos totais e com a clorofila "a". Esse parâmetro sofre influência na presença de detritos orgânicos e outras substâncias, Carvalho et al. (2017, p. 45) elencam a ocorrência de "zinco, ferro, compostos de manganês e areia, resultantes do processo natural de escoamento superficial ou da ação antrópica, como lançamentos de esgotos e efluentes das atividades industriais". Esse indicativo corrobora com o cenário da área de estudo, podendo influenciar nas comunidades biológicas aquáticas e afetar adversamente os usos múltiplos mais preponderantes.

Verificou-se ainda que a DBO apresentou forte correlação com os parâmetros clorofila "a" e os macronutrientes fósforo total e nitrogênio total. Esse fato pode-se justificar em virtude da descarga de efluentes não tratados em corpos hídricos receptores que podem causar o fenômeno da eutrofização decorrente do enriquecimento do corpo hídrico por macronutrientes, principalmente fósforo e nitrogênio, tornando-o propenso à proliferação de algas, que por sua vez, pode formar uma camada de biofilme que impede a penetração de luz nas camadas inferiores, diminuindo a quantidade de oxigênio dissolvido, e consequentemente causando a mortandade das comunidades aquáticas (SPERLING, 2014).

Corroborando com os resultados obtidos, Jardim et al. (2014) explicam que a regiões com extensos períodos de estiagem, nos quais a ausência de chuvas provoca uma baixa taxa de escoamento da água e associado a um balanço ideal de nutrientes e à elevação da temperatura, pode propiciar condições favoráveis à ocorrência de florações de algas e de cianobactérias na água dos reservatórios. Os fenômenos de floração delas estão relacionados a processos de eutrofização que acabam comprometendo os usos múltiplos da água (JARDIM et al., 2014).

Por meio da representação gráfica do Biplot (entre CP1 e $\mathrm{CP} 2$ ), permitiu-se caracterizar as variáveis que mais discriminaram influência na formação dos agrupamentos para o período chuvoso e seco (Figura 03). Considerou-se para a pesquisa os meses de janeiro a junho como período chuvoso e julho a dezembro como período seco, conforme proposto por Silva, Lúcio e Spyrides (2012).

Os resultados mostraram que apesar da influência da sazonalidade na qualidade das águas existe uma predominância de parâmetros comuns aos dois momentos, sendo eles: STD, SAL, OD e COT. Essas variáveis se sobressaem uma vez que o cenário em estudo remete ao recorte espacial inserido no semiárido, influenciando diretamente no regime hídrico , principalmente nos reservatórios com menores dimensões de armazenamento, impactando assim o STD e o SAL em função da variação nas recargas decorrentes das precipitações e escoamento superficiais, promovendo a diluição dos sais, bem como o carreamento de material particulado em suspensão, podendo serem afetados pela ação antrópica decorrente da presença do lançamento de esgotos in natura. Enquanto, o OD estaria relacionado à presença de água nos mananciais, assim como os processos naturais de reoxigenação e desoxigenação. Para tanto, o COT seria proveniente do material bentônico presente no leito dos cursos d'água, os quais podem ser revolvidos em decorrência da ciclagem.

Mediante a análise contatou-se que os reservatórios mais susceptíveis a eutrofização remete a Barragem de Pau dos Ferros e o Açude Flechas no munícipio de José da Penha-RN. Esse cenário pode estar relacionado à presença de atividade agropecuária em seu entorno e ao despejo in natura de esgotos provindos das comunidades próximas.

Os escores formadores das componentes principais que mais se repetiram durante o período especificado na área da BHASCA dentro do período seco foram: STD, CRF e SAL para CP1, na CP2 observou-se maior frequência dos pesos do STD e FT. Diante da presença de fatores relacionados ao processo de eutrofização para as duas componentes, evidenciou-se que as ações antrópicas danosas ao meio ambiente que ocorre nas adjacências da rede de drenagem da bacia, como lançamentos de efluentes não tratados e atividades agropastoris, podem estar alterando a qualidade da água dos reservatórios.

No período chuvoso, percebeu-se que os escores mais influentes na formação da CP1 foram STD e CRF, enquanto a CP2 não obedeceu a um padrão, ou seja, cada ano houve associação com pesos de variáveis distintas. As demais componentes mostraram-se relacionadas à aleatoriedade, possivelmente influenciadas pela ação das chuvas, na qual durante todo o período de monitoramento na área em estudo apresentou valores oscilantes diante da distribuição espaçotemporal irregular das precipitações.

A aplicabilidade da ACP na qualidade da água da Bacia Hidrográfica do Açude Santa Cruz do Apodi apresentou que entre os períodos em estudo avaliados verificaram-se que na formação das componentes principais apresentaram-se acima dos $50 \%$ de variância, com exceção os períodos de 2009, 2011b e 2012b (Tabela 3). Arslan (2011) realizou estudos sobre a aplicabilidade da ACP na qualidade de água da bacia hidrográfica do rio Sakarya na Turquia, e identificou o primeiro componente como responsável por $41,05 \%$ da variância acumulada, além disso, observou variáveis discriminantes na formação dessa componente principal: nitrogênio amoniacal, nitrito, nitrato e ortofosfato. 
Figura 3. Análise de Componentes Principais com base nas variáveis da qualidade de água nos diferentes períodos de monitoramento: a) 2008; b) 2009; c) 2010 d) 2011a; e)2011b; f) 2012a; g) 2012b; h) 2014; i) 2015a; j) 2015 b e k) 2016.

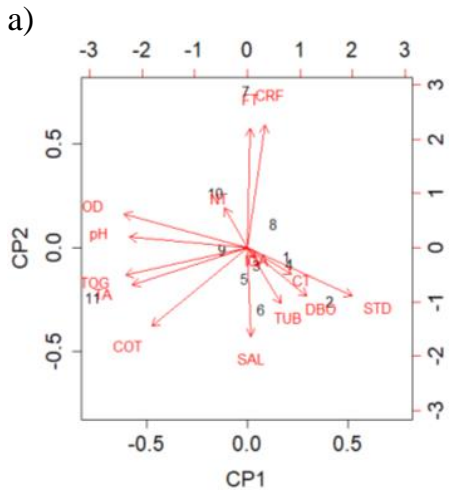

d)

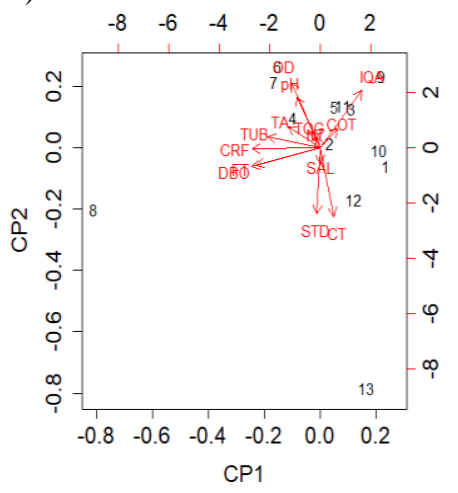

g)

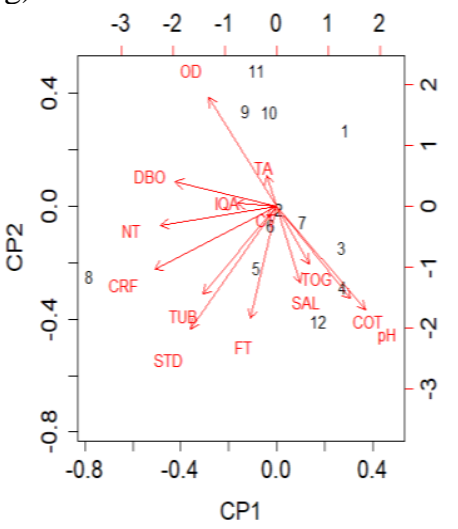

j)

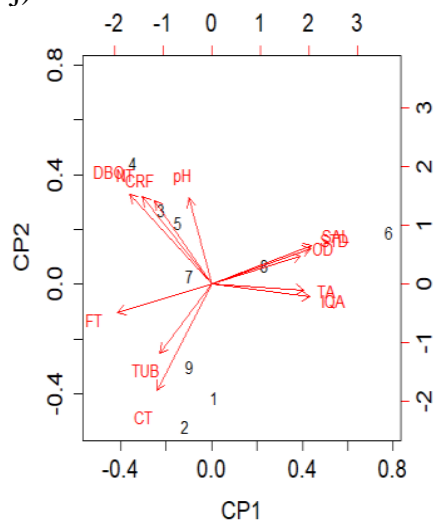

b)

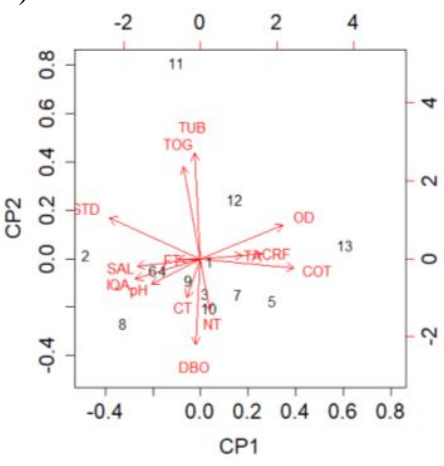

e)

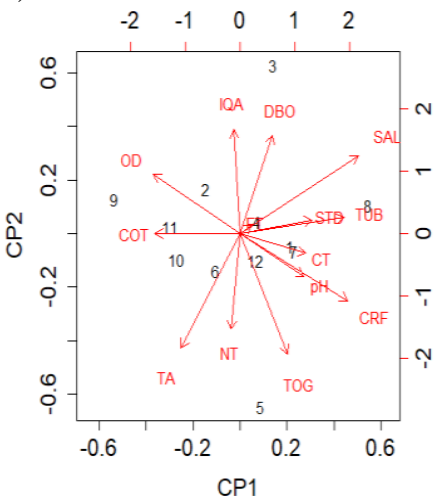

h)

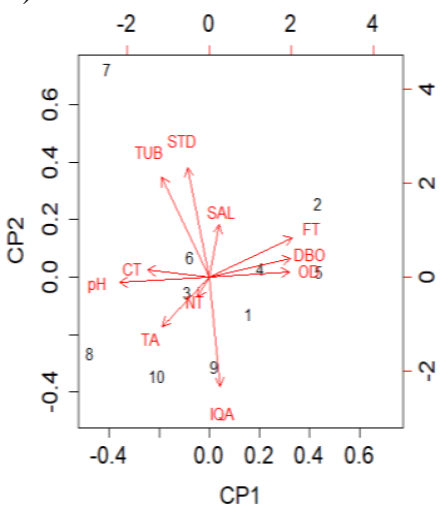

k)

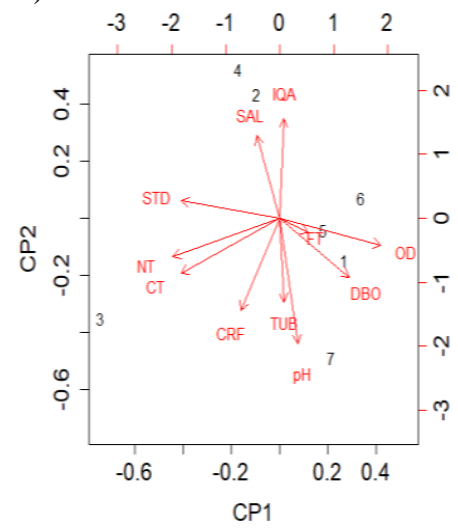

c)

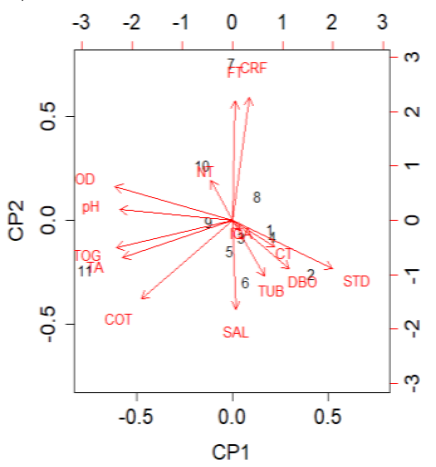

f)

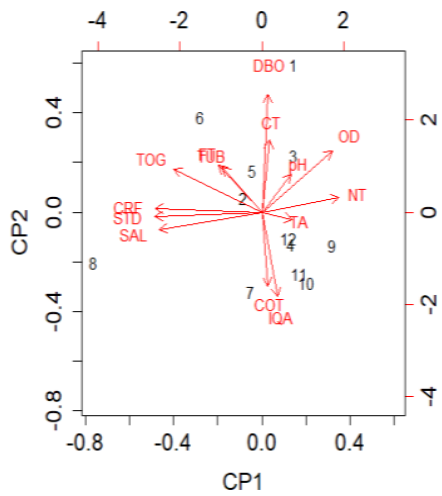

i)

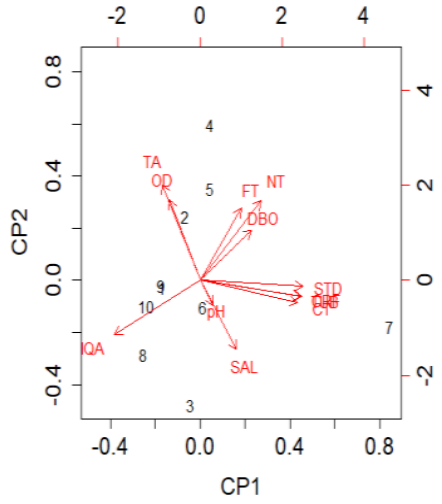


Tabela 3. Componentes selecionadas e seus escores discriminantes formadores entre parâmetros de qualidade de água na Bacia Hidrográfica do Açude Santa Cruz do Apodi nos diferentes períodos de monitoramento

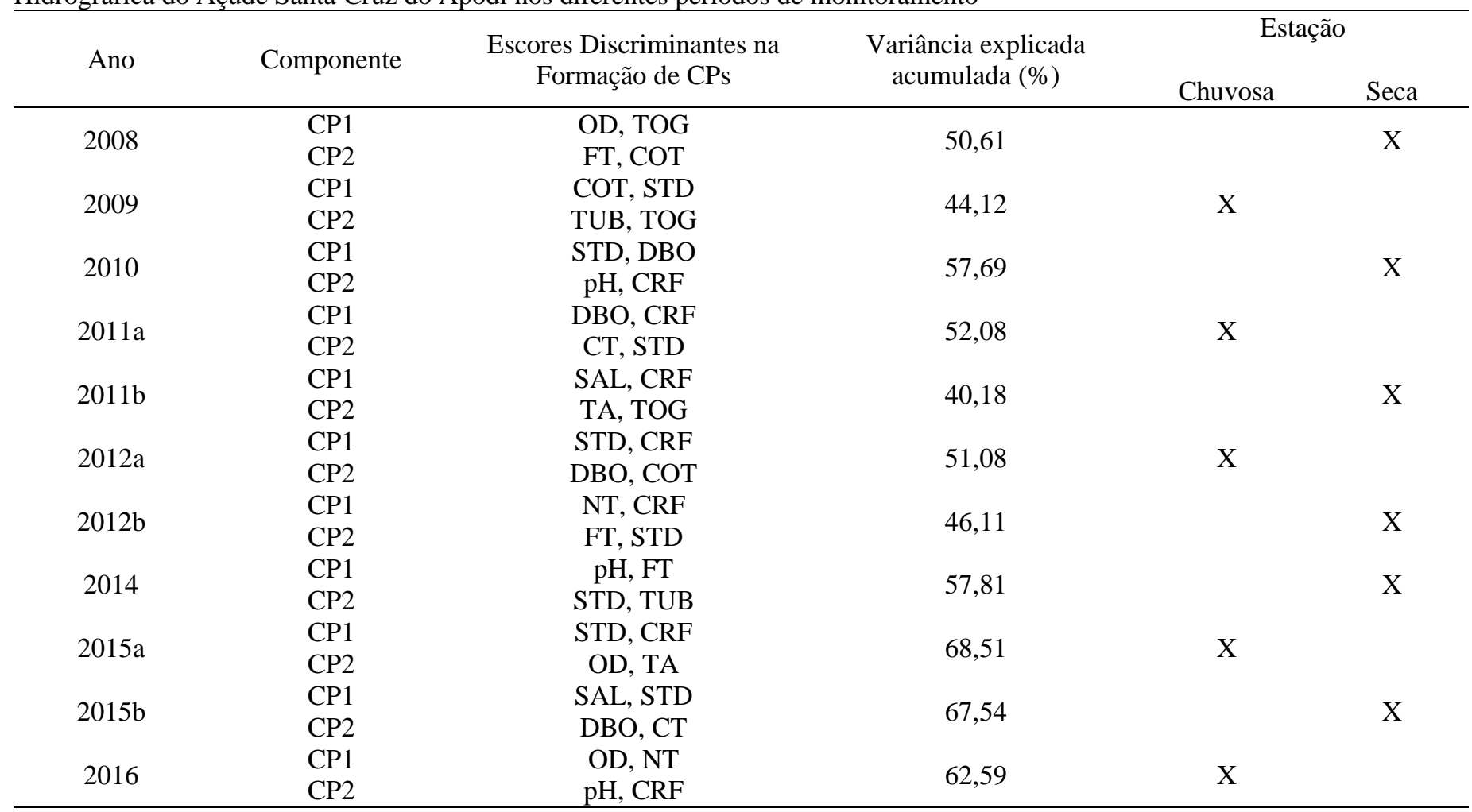

STD: Sólidos Totais Dissolvidos; NT: Nitrogênio Total; DBO: Demanda Bioquímica de Oxigênio; FT: Fósforo Total; COT: Carbono Orgânico Total; OD: Oxigênio Dissolvido (OD); TUB: Turbidez; pH: potencial Hidrogeniônico; TA: Temperatura da Água; CT: Coliformes Termotolerantes; CRF: Clorofila "a"; TOG: Teor de óleos e graxas, e; SAL: Salinidade.

O potencial emprego das variáveis elencadas poderiam otimizar o processo de monitoramento, ao se priorizar o emprego destas em menores intervalos temporais para sua avaliação, podendo complementar a avaliação ao se fazer o emprego dos valores norteadores previstos na Resolução CONAMA $\mathrm{n}^{\circ}$ $357 / 2005$, relacionando aos usos múltiplos preponderantes da água presentes em cada localidade.

A ocorrência da salinidade tem sido um fator discriminante durante o período mais seco do ano, ou seja, durante o período de estiagem, uma vez que as "águas sujeitas às elevadas taxas de evaporação, tornam-se salinas atingindo, em alguns casos, concentrações de sais que impedem seu uso"(PALÁCIO et al., 2011, p. 396).

Essa mesma condição verificou-se no caso da BHASCA, onde a influência das condições de sazonalidade no fluxo hídrico dos rios da região ocasionada por precipitações irregulares e captações de água ao longo da rede de drenagem da bacia, resulta em uma maior concentração dos sais, em decorrência do processo de evaporação, nos açudes localizados em cotas topográficas mais baixas.

Palácio et al. (2011) estudaram à similaridade e fatores determinantes na salinidade das águas superficiais do Ceará e identificaram que a salinidade é definida principalmente pelas condições naturais do solo e do clima da região, mas também em decorrência da influência antrópica. Dessa forma, a concentração de sais no corpo d'água pode variar em todo o espelho, aumentando no período seco e diminuindo no período chuvoso, com maior predisposição ao aumento da salinidade nos locais onde houve intervenção humana.

Observando os escores discriminados formadores das componentes, percebeu-se que a eutrofização na BHASCA está relacionada ao período seco e chuvoso, em virtude da predominância de fatores de ordem química e biológica. Sendo mais presente no período seco, pois há redução das águas dos reservatórios, o que evidencia que as ações antrópicas danosas ao meio ambiente podem está alterando a qualidade da água nos locais de estudo. Os ambientes estudados apresentaram indicadores de clorofila "a", sólidos totais, fósforo total e salinidade, que são fatores associados ao fenômeno da eutrofização em mananciais superficiais.

O regime hidrológico da área de estudo caracterizado por sua distribuição irregular e elevada intensidade de precipitação em um curto intervalo de tempo promove um fenômeno de maior erosão no solo que provoca o assoreamento da carga de sedimentos e, consequentemente, aumenta a concentração de partículas sólidas na rede de drenagem. Além disso, Gonçalves e Rocha (2016, p. 1178) acrescentam que nesse período há um uso e manejo mais intensivo dos solos cultivados, incluindo manuseio de fertilizantes e agroquímicos, que associados à condição de pluviosidade, contribui para o maior aporte de poluentes aos corpos hídricos.

A emissão antropogênica de nutrientes proveniente da ausência e/ou limitação dos sistemas de esgotamento sanitário da área de estudo, bem como a presença de atividades agropecuárias têm acelerado o processo de eutrofização dos reservatórios do 
semiárido, comprometendo a qualidade da água, principalmente por florações de cianobactérias potencialmente tóxicas, que além de oferecerem riscos à saúde humana e animal, causam prejuízos econômicos e alteram a estrutura e o funcionamento dos ecossistemas.

Esse cenário inserisse no contexto dos centros urbanos que sofrem com a carência dos serviços de saneamento básico municipais, que tratam de forma ineficiente seus efluentes líquidos, lançando-os de forma inadequada nas calhas fluviais, além da disposição final irregular dos resíduos sólidos, lançados muitas vezes próximos e/ou montante dos reservatórios. Em estudo realizado por Costa (2019), verificou-se o descuido das concessionárias que, embora realizem a coleta dos efluentes corretamente, não há um tratamento de esgoto eficiente para alguns dos municípios da unidade territorial, o que evidencia um ambiente propício para o índice de desempenho insatisfatório para esse setor.

Palácio et al. (2011), Bertossi et al. (2013) e Barcelos et al. (2017) verificaram em seus estudos que os maiores valores relacionados à salinidade e contaminação orgânica ocorreram durante o período de estiagem, onde há um déficit hídrico. Nesta época, os açudes estão com níveis mais baixos, resultando em uma maior concentração dos elementos inorgânicos e orgânicos em decorrência do processo de evaporação.

Apesar do recorte espacial da bacia hidrográfica em estudo contemplar uma área em franca expansão urbana com predominância da exploração em meio rural, em que ocorrem as atividades antrópicas de agropecuária e prestação de serviços, segundo Silva et al. (2020, p. 398), "a BHASCA vem sofrendo constantes impactos ambientais oriundos das atividades antrópicas que são desenvolvidas em seu entorno, provenientes das constantes descargas de esgotos domésticos e industriais lançados em toda sua extensão". Nesse sentido, em estudo sobre os estados tróficos da Barragem de Pau dos Ferros e da Barragem Santa Cruz, Apodi -RN, Silva (2013) observou altos índices de clorofila e fósforo, classificando-os em eutrófico-hipereutrófico (Pau dos Ferros) e mesotrófico-eutrófico (Santa Cruz), comprometendo, dessa forma, os usos múltiplos da água.

Diante dessa situação, a fiscalização dos recursos hídricos deve ser constante, visando à proteção dos recursos hídricos e da saúde pública. O despejo de efluentes domésticos in natura ou tratados inadequadamente e lançados nos cursos d'água podem motivar a eutrofização antrópica, sendo necessária a intervenção emergencial do poder público e a mobilização da sociedade para a destinação correta dos efluentes de forma a reverter o quadro de degradação dos recursos hídricos.

Entretanto, é valido destacar que procedimentos estatísticos multivariados utilizados para definição da qualidade das águas facilitam o processo de gestão dos recursos hídricos, principalmente auxiliando nas atividades de monitorização e de utilização das águas, uma vez que permite a redução da quantidade de elementos analisados, como também de tempo para análise (GOMES; FRANÇA, 2019).

\section{CONCLUSÃO}

Os corpos hídricos superficiais presentes na Bacia Hidrográfica do Açude Santa Cruz do Apodi apresentam-se susceptíveis à processos de eutrofização potencializados por fenômenos antrópicos ao longo de seu recorte territorial, seja pelo lançamento de efluentes domésticos não tratados pelos municípios que compõem a bacia ou pela prática de atividades agropastoris, que podem estar comprometendo e/ou limitando os usos múltiplos das águas, bem como afetando a manutenção da biodiversidade.

\section{REFERÊNCIAS}

ALVARES C. A.; STAPE J. L.; SENTELHAS P. C.; GONÇALVES J. L. M.; SPAROVEK G. Köppen's climate classificationmap for Brazil. Meteorologische Zeitschrift, n. 22, p. 711-728, 2013. 10.1127/0941-2948/2013/0507

ARSLAN, O. Spatially weighted principal component analysis (PCA) method for water quality analysis. Water Resources, v. 40, n. 3, p.315-324, 2013. 10.1134/S0097807813030111

BACCI, D. L. C.; PATACA, E. M. Educação para a água. Estudos Avançados, São Paulo, v. 22, n. 63, p. 211-226, 2008. 10.1590/S0103-40142008000200014

BARCELOS, A. A.; RAMALHO, F. L.; CABRAL, J. B. P.; ALVES, W. S. Diagnóstico da qualidade das águas do córrego Sucuri (Caçu-Goiás). Revista Brasileira de Geografia Física, v. 10, p. 750-766, 2017. 10.5935/1984-2295.20170049

BeRTOSSI, A. P. A.; MENEZES, J. P. C.; CECÍlIO, R. A.; GARCIA, G, O.; NEVES, M. A. Seleção e agrupamento de indicadores da qualidade de águas utilizando Estatística Multivariada. Semina: Ciências Agrárias, v. 34, p. 2025-2036, 2013. 10.5433/1679-0359.2013v34n5p2025

BRAGA, E. S.; FREITAS, C. B.; MENDES, L. S. A. dos S.; AQUINO, M. D. de. Avaliação da qualidade de águas subterrâneas localizadas no litoral, serra e sertão do Estado do Ceará destinadas ao consumo humano. Revista Águas Subterrâneas, v. 32, p. 17-24, 2017. 10.14295/ras.v32i1.28969

BRASIL. Ministério do Meio Ambiente. Resolução CONAMA $n^{0} 357$, de 15 de junho de 2005. Dispõe sobre a classificação dos corpos de água e diretrizes ambientais para o seu enquadramento, bem como estabelece as condições e padrões de lançamento de efluentes, e dá outras providências. Disponível em: $<$ http://www2.mma.gov.br/port/conama/legiabre.cfm?codlegi=4 59>. Acesso em: 20 fev. 2021.

CARVALHO, A. P. M.; SILVA, J. N.; SANTOS, V. S.; FERRAZ, R. R. Avaliação dos parâmetros de qualidade da água de abastecimento alternativo no distrito de Jamacaru em Missão Velha-CE. Revista de Iniciação Científica, Tecnológica e Artística, v. 7, n. 1, p. 35-51, 2017.

COMPANHIA DE PESQUISA E RECURSOS MINERAIS (CPRM). Geobank - download de arquivos vetoriais. 2016. Disponível em: 〈http://geobank.cprm.gov.br/〉. Acesso em: 01 nov. 2016. 
COSTA, M. A. Análise de serviços de saneamento básico na bacia hidrográfica Apodi-Mossoró com aplicação de sistema de informação geográfica (SIG) livre e gratuito. Trabalho de Conclusão de Curso (Graduação - Engenharia Civil). Mossoró, p. 52. 2019.

GARDIMAN JUNIOR, B. S. Caracterização do processo de poluição das águas superficiais da Bacia Hidrográfica do Rio Jucu, estado do Espírito Santo, Brasil. Revista Agroambiente, v.9, n.3, p. 235-242, 2015. 10.18227/1982-8470ragro.v9i3.2310

GOMES, M. C. R.; FRANCA, R. M. Uso da análise multivariada para subsidiar no monitoramento da qualidade da água subterrânea na bacia sedimentar do Araripe, sul do estado do Ceará. GEOCIÊNCIAS, v. 38, p. 195-205, 2019.

GONÇALVES, D. R. P.; ROCHA, C. Indicadores de qualidade da água e padrões de uso da terra em bacias hidrográficas no Estado do Paraná. Pesquisa Agropecuária Brasileira, v. 51, n. 9, p.1172-1183, 2016. 10.1590/s0100-204x2016000900017

GUEDES, A. F.; TAVARES, L. N.; MARQUES, M. N. N.; MOURA, S. P.; SOUSA, M. N. A. Tratamento da água na prevenção de doenças de veiculação hídrica. Journal of Medicine and Health Promotion, v. 2, p. 452-461, 2017.

HONGYU, K.; SANDANIELO, V. L. M.; OLIVEIRA JUNIOR, G. J. Análise de Componentes Principais: resumo teórico, aplicação e interpretação. Engineering and Science, v. 5, n. 1, 2016. 10.18607/ES201653398

IBGE. Instituto Brasileiro de Geografia e Estatística. Pedologia. Banco de Dados de Informações Ambientais (BDIA). 2018. Disponível

em:

〈https://bdiaweb.ibge.gov.br/\#/consulta/pedologia〉. Acesso em: 05 setembro 2018.

JARDIM, F. A.; SPERLING, E. V.; JARDIM, B. F. M.; ALMEIDA, K. C. B. Fatores determinantes das florações de cianobactérias na água do Rio Doce, Minas Gerais, Brasil. Revista Engenharia Sanitária, v. 19, n. 3, p. 207-2018, 2014. 10.1590/S1413-41522014019000001026

JOSÉ, J. V.; REZENDE, R.; FREITAS, P. S. L.; HONGYU, K.; PERBONI, A.; MARQUES, P. A. A.; DIAS, C. T. S.; COELHO, R. D. et al. Análise multivariada e geoestatística de variáveis físico-hídricas de diferentes solos. Water Resources And Irrigation Management, Campina Grande, v. 2, n. 3, p.121-129, 2013.

MACHADO, T. T. V.; DIAS, J.T.; SILVA, T. C. Evolução e avaliação das políticas públicas para a atenuação dos efeitos da seca no semiárido brasileiro. Gaia Scientia, v. 11, n. 2, p.84-103, 2017. 10.22478/ufpb.1981-1268.2017v11n2.31831

MEDEIROS, M. A. Morfometria de Bacias Hidrográficas no semiárido nordestino: Bacia do Açude Santa Cruz do Apodi RN. Trabalho de Conclusão de Curso (Graduação - Engenharia Civil). Pau dos Ferros, p. 66. 2016.
MORAES, L. F.; CABONGO, O. A. dos S.; POLETO, C. Avaliação da rede de monitoramento de uma bacia hidrográfica do Rio Grande do Sul, Brasil. Acta Brasiliensis, v. 2, p. 74-79, 2018. 10.22571/2526-433893

OLIVEIRA, D. G.; REIS, E. F.; MEDEIROS, J. C.; MARTINS, M. P. O.; UMBELINO, A. S. Correlação espacial de atributos físicos do solo e produtividade de tomate industrial. Revista Agro@mbiente, v. 12, n. 1, p. 1-10, 2018. 10.18227/1982$\underline{\text { 8470ragro.v12i1.4211 }}$

OLIVEIRA, T. M. B. F.; SOUZA, L. D.; CASTRO, S. S. L. Dinâmica da série nitrogenada nas águas da bacia hidrográfica Apodi/Mossoró - RN - Brasil. Eclética Química, v. 34, n. 3, p. 17-26, 2009. 10.1590/S0100-46702009000300002

OLIVEIRA, M. A.; QUEIROZ, R. A. C. A poluição no Rio Mossoró (RN) e a ação intervencionista do Ministério Público. In: ENCONTRO NACIONAL DA ASSOCIAÇÃO NACIONAL DE PÓS-GRADUAÇÃO E PESQUISA EM AMBIENTE E SOCIEDADE, 4., 2008, Brasília. Anais... Brasília, 2008. p. 1-14. Disponível em: $<$ http://www.anppas.or.br/encOntro4/cd/ARQUIVOS/GT-5181004-20080517230550.PDF>. Acesso em: 7 out. 2019

PALÁCIO, H. A. Q.; ARAÚJO NETO, J. R.; MEIRELES, A. C. M.; ANDRADE, E. M.; SANTOS, J. C. N.; CHAVES, L. C. G. Similaridade e fatores determinantes na salinidade das águas superficiais do Ceará, por técnicas multivariadas. Revista Brasileira de Engenharia Agrícola e Ambiental, v. 15, n. 4, p. 395-402, 2011. 10.1590/S1415-43662011000400011

PRODANOV, C. C; FREITAS, E. C. Metodologia do trabalho científico: Métodos e Técnicas da Pesquisa e do Trabalho Acadêmico. $2^{\text {a }}$ ed. Universidade Feevale - Novo Hamburgo, Rio Grande do Sul, 2013.

PROGRAMA ÁGUA AZUL. Relatórios: águas superficiais. $2018 . \quad$ Disponível em: $<$ http://programaaguaazul.ct.ufrn.br/relatorios/aguas_superficiai s/>. Acesso em: 11 set. 2018.

ROCHA, C. H. B.; PEREIRA, A. M. Análise multivariada para seleção de parâmetros de monitoramento em manancial de Juiz de Fora, Minas Gerais. Revista Ambiente \& Água, v. 11, n. 1, p. 176-187, 2016. 10.4136/ambi-agua. 1590

SILVA, W. B.; BEZERRA, J. M.; FEITOSA, A. P.; SILVA, P. C. M.; REGO, A. T. A. Uso e Ocupação do Solo na Bacia Hidrográfica do Açude Santa Cruz do Apodi/RN. Anuário do Instituto de Geociências, v. 43, p. 397-407, 2020.

SILVA, A. P. C. Biomonitoramento da qualidade de água e percepção ambiental na bacia hidrográfica Apodi-Mossoró - RN. 2013. 101 f. Dissertação (Mestrado) - Curso de Programa Regional de Pós-Graduação em Desenvolvimento e Meio Ambiente/PRODEMA, Universidade Federal do Rio Grande do Norte, Natal, 2013. 
SILVA, C. M. S.; LÚCIO, P. S.; SPYRIDES, M. H. C. Distribuição espacial da precipitação sobre o Rio Grande do Norte: estimativas via satélites e medidas por pluviômetros. Revista Brasileira de Meteorologia, v. 3, n. 27, p.337-346, 2012. 10.1590/S0102-77862012000300008

SOUZA, A. C. M.; SILVA, M. R. F.; DIAS, N. D. Gestão de recursos hídricos: o caso da bacia hidrográfica Apodi/Mossoró (RN). Irriga, v.1, n.1, p.280-296, 2012. $\underline{10.15809 / \text { irriga.2012v1n01p280 }}$

SPERLING, M. V. Introdução à qualidade das águas e ao tratamento de esgotos. 4. Ed. Belo Horizonte: Departamento de Engenharia Sanitária e Ambiental - UFMG, 2014, 452p.
SPINELLI, J. A. Estudos estados brasileiros: Rio Grande do Norte 2000-2013. 1 ed. São Paulo: Fundação Perseu Abramo, 2014.

STOLF, D. F.; MOLZ, S. Avaliação microbiológica da água utilizada para consumo humano em uma propriedade rural de Taió - SC. Revista Saúde e Meio Ambiente, v. 6, n. 1, p. 96-106, 2017. 10.24302/sma.v6i1.1104

VARELA, A. W. P.; SANTOS, R. M.; SOUZA, P. H. C.; SANTOS, M. L. S. C. Avaliação da qualidade das águas superficiais a montante e jusante do furo do Muriá, Estuário de Curuçá (Pará-Brasil). In: Congresso Técnico Científico da Engenharia e da Agronomia, 2017, Pará. Anais... Pará, 2017. p. $1-5$. 